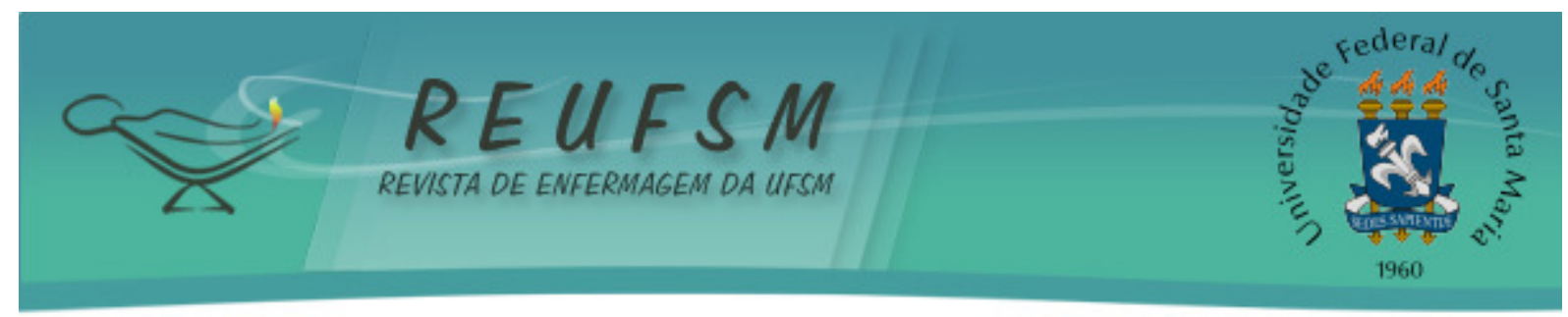

ARTIGO DE REVISÃO

\title{
VANTAGENS E USOS DO TESTE RÁPIDO MOLECULAR PARA TUBERCULOSE: UMA REVISÃO INTEGRATIVA
}

\author{
ADVANTAGE AND USAGE OF MOLECULAR FAST TEST FOR TUBERCULOSIS: AN \\ INTEGRATIVE REVIEW
}

\section{VENTAJAS Y USOS DE LA PRUEBA RÁPIDA MOLECULAR DE LA TUBERCULOSIS: UNA REVISÓN INTEGRADORA}

Daniela Furtado Rodrigues de Andrade ${ }^{1}$ Mariana Lustosa de Carvalho ${ }^{2}$ Telma Maria Evangelista de Araújo ${ }^{3}$ Marcos André Siqueira de Sousa ${ }^{4}$ Laís Carvalho de Sá ${ }^{5}$

Doi: $10.5902 / 2179769221894$

Érica Juliana Benício Araújo ${ }^{6}$

RESUMO: Objetivo: investigar na literatura as vantagens e usos do teste rápido molecular para diagnóstico da tuberculose. Método: revisão integrativa da literatura com condução da questão norteadora elaborada por meio da estratégia PICO ( $\mathrm{P}=\mathrm{Paciente}$ ou Problema, $\mathrm{I}=$ Intervenção, $\mathrm{C}=$ Comparação ou controle, $\mathrm{O}=$ =utcomes ou desfechos). Foi realizada uma busca nas bases de dados BVS, LILACS, MEDLINE e Science Direct com artigos disponíveis na integra, de forma eletrônica publicados entre 2008-2015. Resultados: o teste molecular Gene Xpert, atualmente disponibilizado para o diagnóstico da tuberculose, tem a capacidade de detectar a presença do bacilo causador da doença e identificar se a bactéria tem resistência a rifampicina, em duas horas, além de maior sensibilidade e especificidade em relação à baciloscopia. Conclusões: o teste rápido molecular para o diagnóstico de tuberculose foi bem aceito principalmente pela agilidade, constituindo uma forma mais eficaz de controle da doença, possibilitando início mais rápido do tratamento, sendo importante para minimizar a disseminação da doença.

Descritores: Tuberculose; Diagnóstico; Reação em cadeia da polimerase.

ABSTRACT: Aim: to investigate though the literature the advantages and uses of the molecular test for fast tuberculosis diagnosis. Method: integrative review of literature with considering the guiding question elaborated by the PICO ( $P=$ Patient or Problem, $I=$ Intervention, $C=$ Comparison or control, $\mathrm{O}=$ Outcomes) strategy. A research was performed with articles available in full electronically published from 2008 to 2015 in the following databases: Virtual Health Library (VHL), Latin American and Caribbean Health Sciences (LILACS), Medical Literature Analysis and Retrieval System Online (MEDLINE) and Science Direct. Results: The molecular Gene Xpert test, currently available for the diagnosis of tuberculosis, has the ability of detecting the presence of the disease causative bacillus, and identifying if the bacteria is resistant to rifampicin, in the period

\footnotetext{
${ }^{1}$ Enfermeira, Mestranda do Programa de Pós-graduação em Ciências e Saúde da Universidade Federal do Piauí, Teresina-PI, Brasil, email: daniela.furtado@outlook.com

2 Acadêmica de enfermagem. Graduanda da Universidade Federal do Piauí, Teresina-PI, Brasil, email: marianalustosacarvalho@gmail.com

${ }^{3}$ Professora da Universidade Federal do Piauí, Doutora em Saúde Coletiva (UFRJ), Teresina-PI, Brasil, email: telmaevangelista@gmail.com

${ }^{4}$ Enfermeiro. Bacharelado em enfermagem (UFPI), Teresina-PI, Brasil, email: marcosandrs4@gmail.com

${ }^{5}$ Enfermeira. Mestre em Enfermagem (UFPI), Teresina-PI, Brasil, email: laiscarvalgodesa@hotmail.com

${ }^{6}$ Enfermeira. Bacharelado em enfermagem (UFPI), Teresina-PI, Brasil, email: ericajuul@hotmail.com
} 


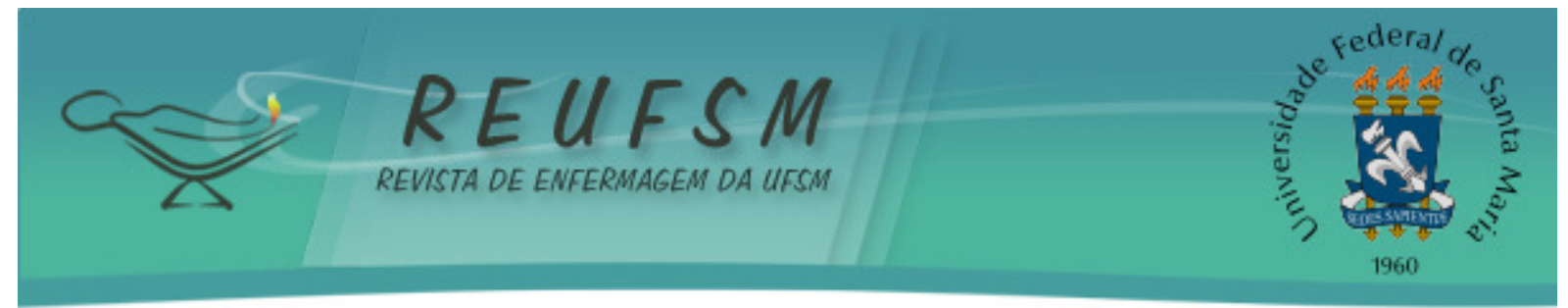

of two hours, besides greater sensitivity and specificity in relation to smear. Conclusions: molecular test for fast tuberculosis diagnosis was well accepted mainly for its speed, enabling a faster onset of treatment, important to minimize the spread of the disease.

Descriptors: Tuberculosis; Diagnosis; Polymerase chain reaction.

RESUMEN: Objetivo: investigar en la literatura las ventajas y usos de la prueba molecular para el diagnóstico rápido de la tuberculosis. Método: revisión integradora de la literatura, a partir de la pregunta guía elaborada por la estrategia PICO ( $P=$ Paciente 0

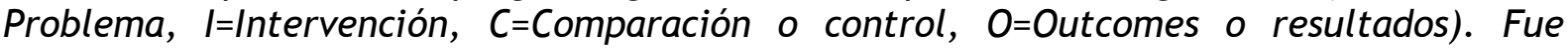
realizada una búsqueda en las bases de datos BVS, LILACS, MEDLINE, Science Directcon artículos completos disponibles, publicados electrónicamente entre 2008-2015. Resultados: la prueba genética Xpert molecular, disponible actualmente para el diagnóstico de la tuberculosis, es capaz de detectar la presencia del bacilo causador de la enfermedad e identificar las bacterias tiene una resistencia a la rifampicina, en dos horas, además de presentar mayor sensibilidad y especificidad con relación a la prueba de local. Conclusiones: la prueba rápida para el diagnóstico molecular de la tuberculosis fue bien aceptada, principalmente por la velocidad, que posibilita un control de la enfermedad más eficaz, permitiendo la iniciación más rápida del tratamiento, lo que es importante para minimizar la propagación de la enfermedad.

Descriptores: Tuberculosis; Diagnóstico; Reacciónen cadena de la polimerasa.

\section{INTRODUÇÃO}

A Tuberculose (TB) continua a ser um problema de saúde global, com estimativa de 10,4 milhões de novos casos e 1,8 milhão de mortes em decorrência da doença em todo o mundo em 2015. ${ }^{1}$ Apesar da incidência de TB e sua taxa de mortalidade terem diminuído desde 1990, a carga global continua a ser substancial devido à lenta taxa de declínio na incidência de TB ( $2 \%$ ao ano). Nesse sentido, tendo em vista o controle efetivo da tuberculose, o diagnóstico laboratorial rápido e efetivo é de extrema importância. ${ }^{2}$

Em dezembro de 2010 a Organização Mundial de Saúde (OMS) aprovou o uso do ensaio de Xpert MTB/RIF depois de analisar as evidências disponíveis por meio de um processo mais amplo de consulta. O exame é denominado Teste Rápido Molecular para Tuberculose (TRM-TB) cuja realização é feita com máquina automatizada GeneXpert, a qual faz a amplificação de ácidos nucléicos utilizados para detecção de DNA do $M$. tuberculosis e triagem de cepas resistentes à rifampicina pela técnica de reação em cadeia da polimerase (PCR) em tempo real. ${ }^{3}$

0 teste apresenta sensibilidade de $88 \%$ e especificidade em pool de $98 \% .^{4-5}$ Foi implantado no Brasil no segundo semestre de 2014 e marcou um início bem-sucedido da biologia molecular para o diagnóstico de TB com alta sensibilidade e especificidade, além de notavelmente reduzir o tempo de resultado do diagnóstico com a economia de custos. Dessa forma, a utilização do teste, antes da cultura, representa agilidade na confirmação do resultado e com isso, o tratamento pode ser iniciado mais precocemente, sem a necessidade de se aguardar a confirmação pela cultura. ${ }^{6}$

Tendo em vista a importância de um diagnóstico preciso e precoce para o controle da TB, questiona-se quais as vantagens do teste rápido molecular em comparação à baciloscopia? Em que casos se pode usar esse método? Este estudo tem como objetivo investigar na literatura as vantagens e usos do teste rápido molecular para diagnóstico da tuberculose. 


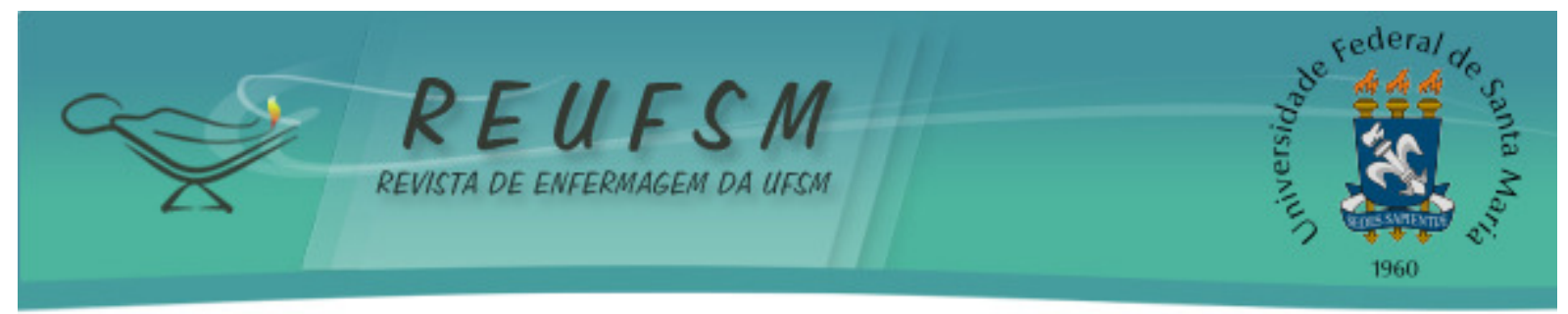

MÉTODO

Trata-se de uma revisão integrativa $(\mathrm{RI})$ da literatura científica acerca do teste rápido molecular para TB. A RI consiste na construção de uma análise ampla da literatura, contribuindo para discussões sobre métodos e resultados de pesquisas, assim como reflexões sobre a realização de futuros estudos. ${ }^{7}$

Dessa maneira, foi operacionalizada a partir das seguintes etapas: identificação do tema e seleção da questão de pesquisa; estabelecimento de critérios de inclusão e exclusão; identificação dos estudos pré-selecionados e selecionados; categorização dos estudos selecionados; análise e interpretação dos resultados e apresentação da revisão/síntese do conhecimento. ${ }^{7}$

A pergunta norteadora do processo revisional foi construída por meio da

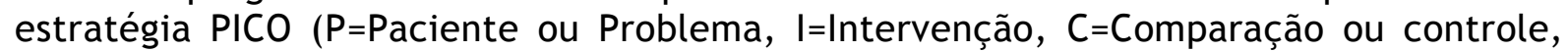
$\mathrm{O}=$ =utcomes ou desfechos) e consistiu em: quais as vantagens e usos do teste rápido molecular para tuberculose $?^{8}$ Para elaboração da pesquisa foi realizada uma busca nas bases de dados Biblioteca Virtual em Saúde (BVS), Literatura Latino-Americana e do Caribe em Ciências da Saúde (LILACS) e Medical Literature Analysis and Retrieval System on-line (MEDLINE), Science Direct, utilizando-se a combinação de descritores controlados, cadastrados no Medical Subject Headings (MesH): Tuberculosis; Diagnosis; Polymerase Chain Reaction.

Os critérios de inclusão foram: artigos de pesquisa na temática teste rápido molecular para tuberculose; disponíveis na íntegra online; nos idiomas português, inglês ou espanhol; recorte temporal de 2008 a 2015, pois o ponto inicial está sustentado por se tratar de um assunto relativamente novo no cenário brasileiro, e o teste rápido ter sido implantado recentemente no Brasil com intuito de diagnosticar casos de tuberculose com maior rapidez. Como critério de exclusão definiu-se: artigos repetidos nas bases de dados; artigos sem resumo nas bases de dados ou incompletos.

A seleção dos estudos foi realizada de forma independente e em duplo cego, por dois membros da equipe de revisão. Desacordos quando não resolvidos por discussão ou consenso pela dupla de examinadores foram determinados por um terceiro da equipe de revisão. Para a análise dos dados, foi utilizado o software Interface de $R$ pour lês Analyses Multidimensionnelles de Textes et de Questionnaires (IRAMUTEC) ${ }^{9}$. Este software organiza a distribuição do vocabulário de forma facilmente compreensível e visualmente clara (análise de similitude e nuvem de palavras). ${ }^{10}$

Os artigos foram classificados segundo o nível de evidência, considerando: 1 evidências provenientes de revisão sistemática ou metanálise de relevantes ensaios clínicos randomizados controlados ou oriundas de diretrizes clínicas baseadas em revisões sistemáticas de ensaios clínicos randomizados controlados; 2 - evidências de pelo menos um ensaio clínico randomizado controlado bem delineado; 3 - ensaios clínicos bem delineados sem randomização; 4 - estudos de coorte e de caso-controle bem delineados; 5 - revisão sistemática de estudos descritivos e qualitativos; 6 evidências derivadas de um único estudo descritivo ou qualitativo; 7 - opinião de autoridades ou comitês de especialistas incluindo interpretações de informações não baseadas em pesquisas. ${ }^{11}$

Os aspectos éticos foram respeitados, uma vez que todos os autores consultados foram mencionados no texto.

Para a continuação da realização do estudo, foram localizados 48 artigos, dos quais 15, após os critérios de inclusão, foram selecionados para o processamento e análise, 


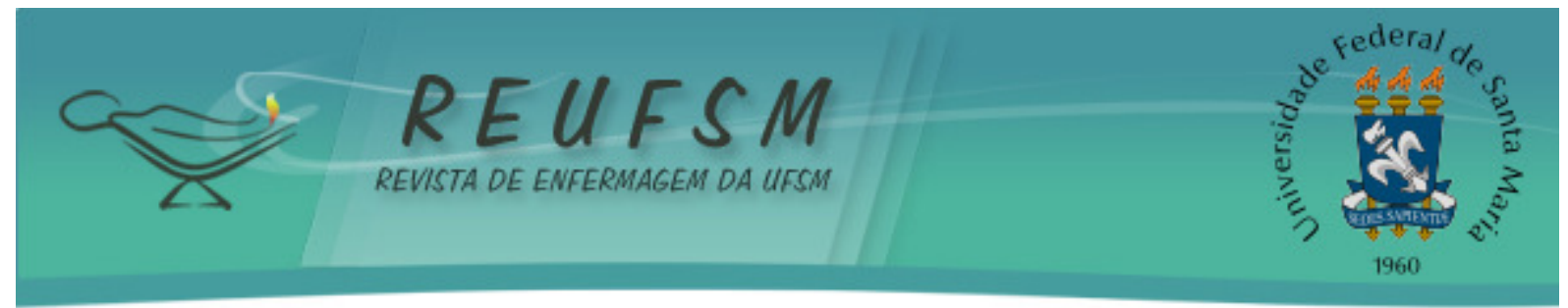

conforme o fluxograma abaixo. Os resultados foram expostos e analisados à luz do referencial de análise. ${ }^{10}$

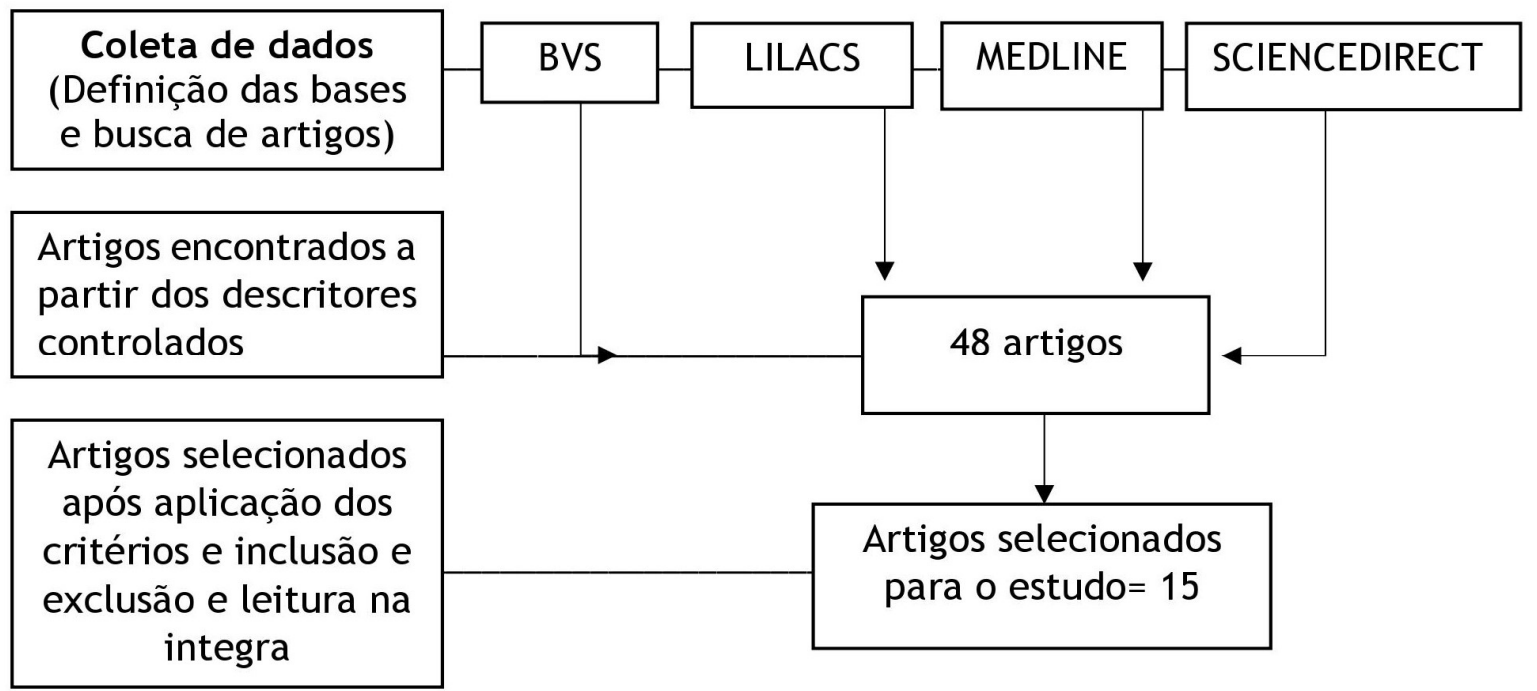

Fluxograma 1: Seleção dos artigos para processamento e análise

\section{RESULTADOS}

Para a realização da análise textual pelo software IRAMUTEQ, procedeu-se a separação do corpus em um único arquivo, dividido em 15 unidades de texto iniciais (UCl), sendo retidos 132 segmentos de texto dentre um total de 165, representando as unidades de contexto elementar (UCE), sendo utilizados $80,00 \%$ do corpus para análise. Os artigos utilizados para a construção do corpus se encontram expostos no quadro I, organizados de acordo com o título, nível de evidência, periódico e ano de publicação.

Conforme as variáveis do estudo: número do artigo, base de dados e ano de publicação, a Classificação Hierárquica Descendente (CHD) identificou cinco classes semânticas a partir da análise dos domínios textuais e interpretação dos significados, resultando nas classes: 1- Vantagens do uso TRM-TB; 2- Confiabilidade no diagnóstico pelo TRM-TB; 3- Uso do teste para detecção de Mycobacterium tuberculosis; 4- Teste rápido molecular Xpert MTB/RIF no diagnóstico da tuberculose; 5- Capacidade de detecção da resistência à Rifampicina.

A análise hierárquica descendente (CHD) distribuiu as classes, conforme a análise lexical do material textual, de acordo com as expressões mais frequentes dos segmentos, e os artigos pelos quais foram extraídos, por ordem de significância, conforme exposto abaixo:

\section{Classe 1. Vantagens do uso do TRM-TB.}

A classe 1 apresenta 21 UCEs, correspondendo a 15,9\% do corpus e está associada a todas as classes. Os vocábulos mais frequentes e significativos destes segmentos de textos são: modelo, impacto, desenvolvimento, custo-benefício, necessidade, implantação ( $\mathrm{p}<$ 0,0001), extraídas por ordem de significância dos artigos 13, 10 e 05 conforme classificados no quadro 1. 


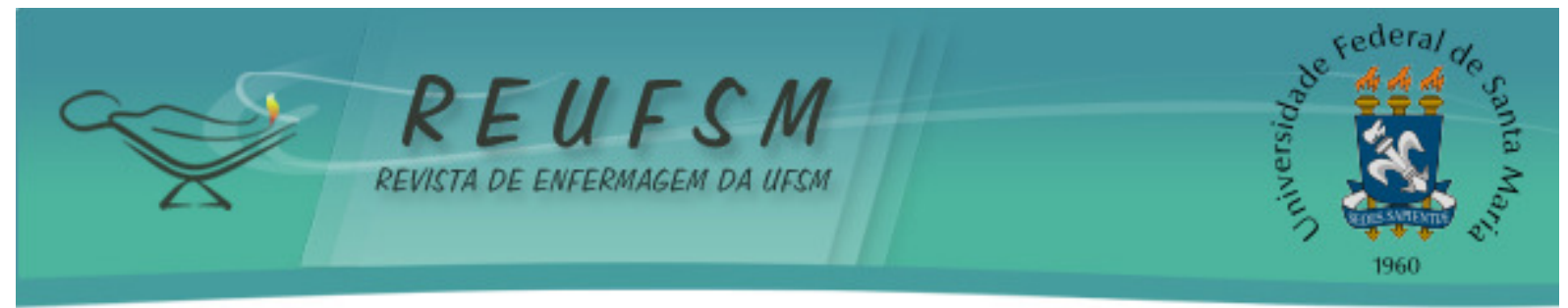

Classe 2: Confiabilidade no diagnóstico pelo TRM-TB.

A classe 2 apresenta 19 UCE's de 132, correspondendo a 14,4\% do corpus e está associada diretamente à classe 3. As expressões mais frequentes destes segmentos de textos são: método, mostrar, confiável, microscópio, diagnóstico $(p<0,0001)$, extraídas predominantemente dos artigos 08, 11, 04 e 14, seguindo ordem de significância, descritos no quadro 1.

Classe 3: Uso do teste para a detecção de Mycobacterium tuberculosis.

A classe 3 apresenta 33 UCE's de 132, respondendo por $25 \%$ do corpus e está associada diretamente à classe 2 . Os vocábulos mais frequentes e significativos destes segmentos de textos são: positivo, negativo, amostra, Mycobacterium, tuberculosis, resultado $(p<0,0001)$, extraídas predominantemente dos artigos 11,08 e 11, por ordem de significância.

\section{Classe 4. Teste rápido molecular Gene Xpert MTB/RIF no diagnóstico da tuberculose.}

A classe 4 apresenta 31 UCEs, correspondendo a 23,5\% do corpus e está associada diretamente à classe 5 . Os vocábulos mais frequentes e significativos destes segmentos de textos são: MTB, molecular, gene, RIF, Xpert, rápido, tuberculose, teste $(p<0,0001)$, extraídas predominantemente dos artigos 15, 07 e 05 por ordem de significância, de acordo com o quadro 1.

Classe 5. Capacidade de detecção da resistência à Rifampicina.

A classe 5 apresenta 28 UCEs de 132, correspondendo a $21,1 \%$ do corpus e está associada diretamente à classe 4 . Os vocábulos mais frequentes e significativos destes segmentos de textos são resistencia, Rifampicina, detecção, mutação, resistente ( $p$ < 0,0001), extraídas predominantemente dos artigos 14, 12, 04 e 07 por ordem de significância, conforme o quadro abaixo. 


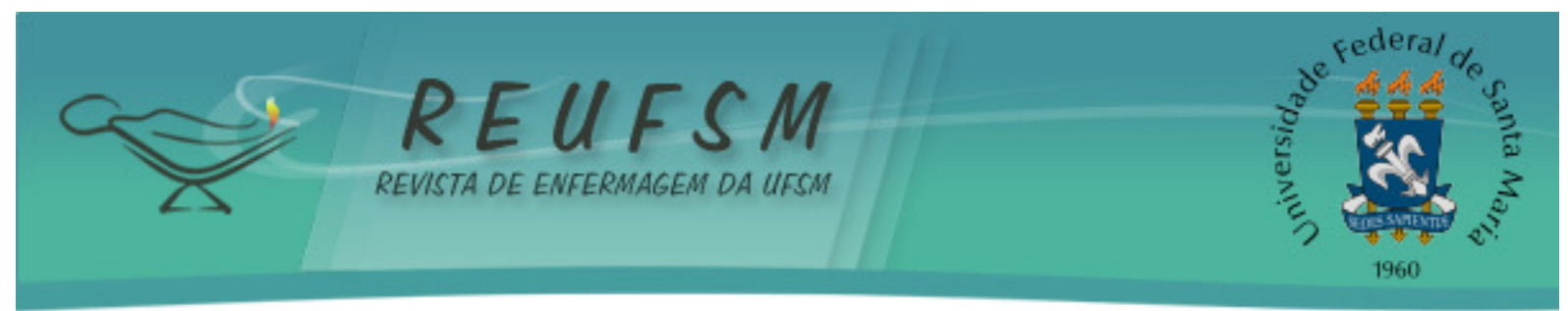

Quadro I: Artigos que colaboraram para a composição do corpus, segundo o título, nível de evidência, periódico e ano de publicação.

\begin{tabular}{|c|c|c|c|c|}
\hline $\begin{array}{l}N^{\circ} \mathrm{DO} \\
\text { ARTIGO }\end{array}$ & TÍTULO DO ARTIGO & $\begin{array}{l}\text { NÍVEL DE } \\
\text { EVIDÊNCIA }\end{array}$ & PERIÓDICO & ANO \\
\hline 1 & $\begin{array}{c}\text { Evaluation of methods for detection and } \\
\text { identification of mycobacterium species in } \\
\text { patients suspected of having pulmonary } \\
\text { tuberculosis }\end{array}$ & - & $\begin{array}{l}\text { Brazilian Journal } \\
\text { of Microbiology }\end{array}$ & 2008 \\
\hline 2 & $\begin{array}{l}\text { Xpert } \circledast \text { MTB/RIF assay: development, } \\
\text { evaluation and implementation of a new rapid } \\
\text { molecular diagnostic for tuberculosis and } \\
\text { rifampicin resistance }\end{array}$ & II & Future Medicine & 2011 \\
\hline 3 & $\begin{array}{c}\text { Xpert } ₫ \mathrm{mtb} / \text { rif no diagnóstico da tuberculose } \\
\text { pulmonar }\end{array}$ & III & BRATS & 2011 \\
\hline 4 & $\begin{array}{l}\text { Tuberculosis drug resistance testing by } \\
\text { molecular methods: Opportunities and } \\
\text { challenges in resource limited settings }\end{array}$ & IV & $\begin{array}{l}\text { Journal of } \\
\text { Microbiological } \\
\text { Methods }\end{array}$ & 2011 \\
\hline 5 & $\begin{array}{l}\text { The accuracy of the Xpert }{ }^{\circledR} \text { MTB/RIF assay } \\
\text { compared to smear microscopy and culture for } \\
\text { detecting pulmonary tuberculosis and }\end{array}$ & & $\frac{\begin{array}{c}\text { Clinical } \\
\text { Epidemiology }\end{array}}{\underline{\text { and Global }}}$ & 2013 \\
\hline & $\begin{array}{l}\text { rifampicin resistance in adults } \\
\text { The accuracy of the Xpert } \otimes M T B / R I F \text { assay for }\end{array}$ & 1 & $\underline{\text { Health }}$ & \\
\hline 6 & $\begin{array}{l}\text { detecting pulmonary tuberculosis and } \\
\text { rifampicin resistance in adults: Summary of } \\
\text { the evidence and implications for public health } \\
\text { programmes }\end{array}$ & I & $\frac{\frac{\text { Clinical }}{\text { Epidemiology }}}{\underline{\text { and Global }}}$ & 2013 \\
\hline 7 & $\begin{array}{l}\text { Molecular Approaches and Biomarkers for } \\
\text { Detection of Mycobacterium tuberculosis }\end{array}$ & II & $\begin{array}{l}\text { Clinics in } \\
\text { Laboratory } \\
\text { Medicine }\end{array}$ & 2013 \\
\hline 8 & $\begin{array}{c}\text { Comparison of molecular and immunological } \\
\text { methods for the rapid diagnosis of smear- } \\
\text { negative tuberculosis }\end{array}$ & II & $\begin{array}{l}\text { INT J TUBERC } \\
\text { LUNG DIS }\end{array}$ & 2013 \\
\hline 9 & $\begin{array}{l}\text { Accuracy of polimerase chain reaction for the } \\
\text { diagnosis of pleural tuberculosis }\end{array}$ & II & $\begin{array}{l}\text { Respiratory } \\
\text { Medicine } \\
\text { International }\end{array}$ & 2014 \\
\hline 10 & $\begin{array}{c}\text { Transmission, prevention and management of } \\
\text { drug resistant tuberculosis }\end{array}$ & ॥ & $\begin{array}{l}\text { Journal of } \\
\text { Infectious } \\
\text { Diseases }\end{array}$ & 2014 \\
\hline 11 & $\begin{array}{c}\text { Evaluation and Comparison of Molecular and } \\
\text { Conventional Diagnostic Tests for Detecting } \\
\text { Tuberculosis in Korea, } 2013\end{array}$ & II & $\begin{array}{l}\text { Osong Public } \\
\text { Health and } \\
\text { Research } \\
\text { Perspectives }\end{array}$ & 2014 \\
\hline 12 & $\begin{array}{c}\text { Molecular Diagnosis of Tuberculosis and Drug } \\
\text { Resistance }\end{array}$ & & $\begin{array}{l}\text { Respiratorylnfec } \\
\text { tions }\end{array}$ & 2014 \\
\hline 13 & $\begin{array}{l}\text { Impact and cost-effectiveness of current and } \\
\text { future tuberculosis diagnostics: the } \\
\text { contribution of modelling }\end{array}$ & V & $\begin{array}{l}\text { INT J TUBERC } \\
\text { LUNG DIS }\end{array}$ & 2014 \\
\hline 14 & $\begin{array}{c}\text { OrtaPrevalanslıBölgedeAkciğerveAkciğerDışıTü } \\
\text { berkülozTanısındaXpert MTB/RIF } \\
\text { TestininDeğerlendirilmes }\end{array}$ & I & $\begin{array}{l}\text { MIKROBIYYOLOJI } \\
\text { BÜLTENI }\end{array}$ & 2014 \\
\hline 15 & $\begin{array}{l}\text { Cost-effectiveness analysis of the Xpert } \\
\text { MTB/RIF assay for rapid diagnosis of suspected } \\
\text { tuberculosis in an intermediate burden area }\end{array}$ & II & $\begin{array}{l}\text { Journaloflnfecti } \\
\quad \text { on }\end{array}$ & 2015 \\
\hline
\end{tabular}




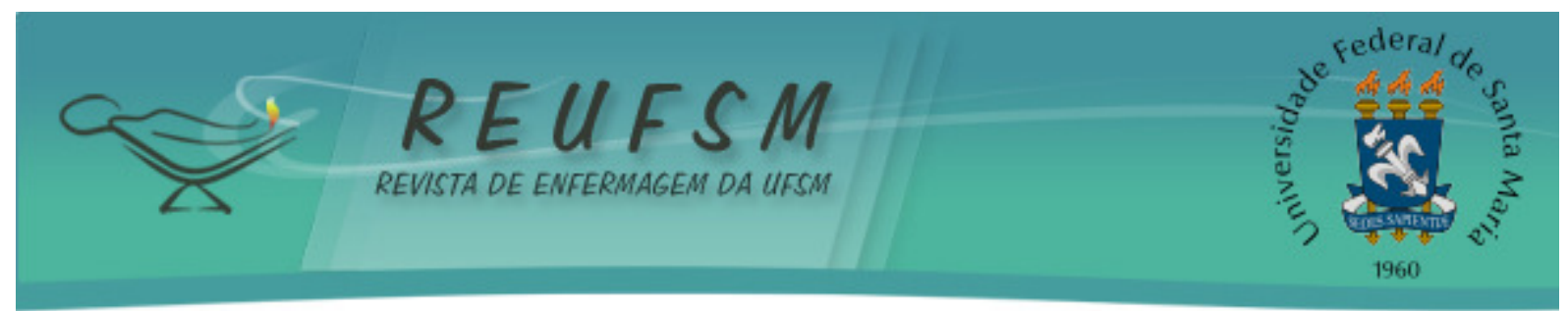

Segundo a figura 2, a nuvem de palavras gerada pelo IRAMUTEQ detectou as palavras de maior significância foram: teste, tuberculose, rápido, RIF, MTB, molecular e confiável. Pode-se compreender por meio dos vocábulos, que existe a confiabilidade no diagnóstico da tuberculose usando o teste rápido molecular Xpert MTB/RIF.

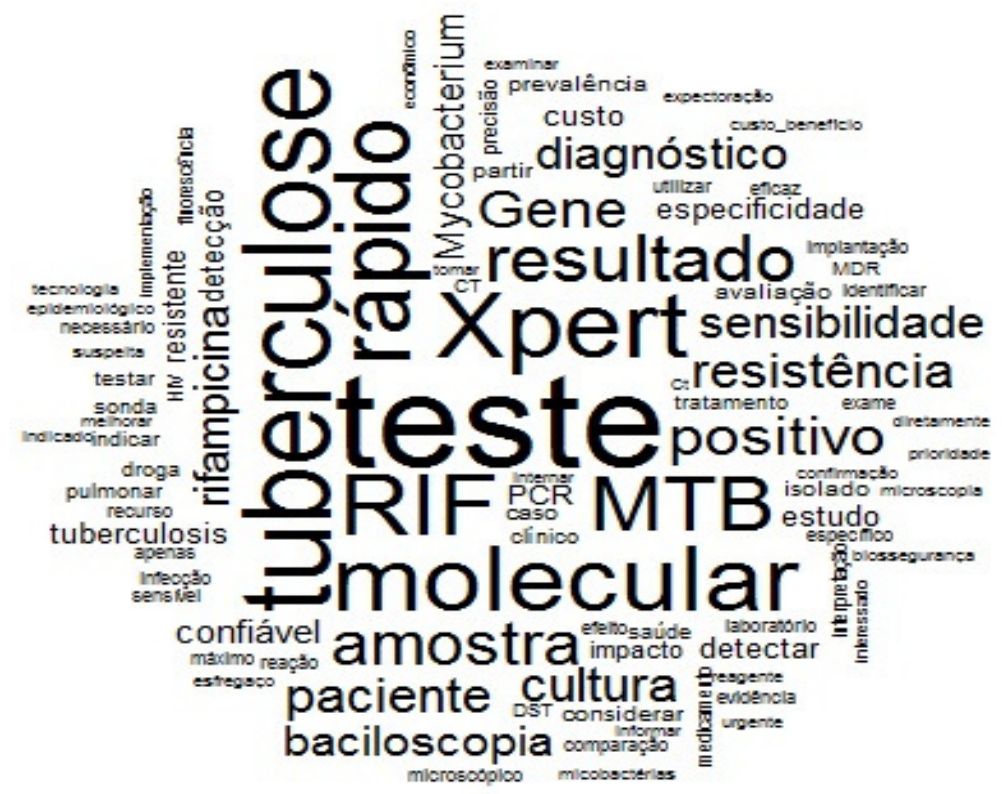

Figura 2: Nuvem de palavras.

\section{DISCUSSÃO}

0 período de transmissibilidade do bacilífero é um dos fatores primordiais para o surgimento de novos casos de Tuberculose e perpetuação da doença do mundo. Logo, o diagnóstico rápido da TB permite o início do tratamento medicamentoso e diminui o número de pessoas infectadas pelo indivíduo doente. ${ }^{12-13}$

Depois de um século de estagnação em relação às novas tecnologias para o diagnóstico da TB, as novas tecnologias de base molecular com sistemas automatizados estão sendo incorporadas para o diagnóstico da TB. ${ }^{14}$ Dentre os testes moleculares existentes, o teste Xpert ${ }^{\circledR}$ MTB/RIF foi escolhido para avaliação desta revisão integrativa, visto ser o utilizado pelo Sistema Único de Saúde do Brasil.

De acordo com o estudo, ${ }^{15}$ o sistema de diagnóstico GeneXpert foi originalmente desenvolvido para a detecção de antraz em instalações de triagem do Serviço Postal dos Estados Unidos. Esta aplicação exigiu o desenvolvimento de uma plataforma autossuficiente, totalmente integrada e automatizada, operada com conhecimento técnico mínimo.

A diferença do sistema GeneXpert para os demais testes de amplificação de ácidos nucléicos utilizados na detecção de TB é que a plataforma do dispositivo de teste, o GeneXpert, integra e automatiza os três processos (preparação de amostras, amplificação e detecção), necessários para a PCR em tempo real baseada em testes moleculares. ${ }^{12}$

Para a execução do teste, a amostra é tratada com um reagente contendo $\mathrm{NaOH}$ e isopropanol, o que reduz substancialmente os riscos biológicos, uma vez que diminui a viabilidade da M. tuberculosis por, pelo menos, seis logs (106 vezes o número de microorganismos viáveis). O teste Xpert ${ }^{\circledR}$ MTB/RIF utiliza cartucho de uso único com múltiplas câmaras que são pré-carregadas com tampões líquido e esferas de reagente 


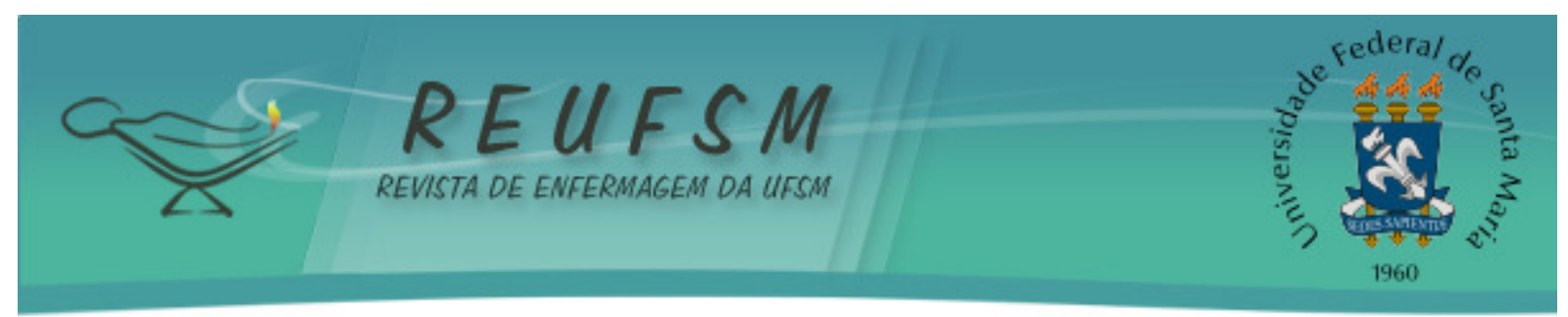

liofilizado necessários para o processamento da amostra e extração de DNA, contendo todos os elementos necessários para a reação, incluindo reagentes liofilizados, tampões líquidos e soluções de lavagem. ${ }^{5,12-16}$

Estudos $^{12-15}$ relatam que, dentre suas principais vantagens, o teste pode fornecer resultados em um laboratório local, em aproximadamente 2 horas, podendo ser realizado por técnicos sem qualificação específica, com eficaz contenção de risco biológico. Como o sistema integra e automatiza totalmente as etapas de extração da amostra, amplificação e detecção em um cartucho, não há necessidade de manipulação do fragmento e, desta forma, o risco de contaminação cruzada é substancialmente reduzido.

Além disso, a plataforma de teste é modular, com cada módulo de processamento, independentemente, um cartucho de cada vez. Máquinas com 1, 4, 16 e 48 módulos estão disponíveis, permitindo que vários ensaios a serem executados simultaneamente e de forma independente. Dessa forma, os cartuchos podem ser carregados e processados individualmente (sem a necessidade de formação de lotes) em combinação com a natureza modular do instrumento, permitindo o processamento das amostras em tempo real. ${ }^{12,15}$

Dentre as desvantagens, os estudos apresentam a necessidade de computador integrado para a análise dos dados, bem como energia elétrica estável e ininterrupta. Outro grande problema na sua implantação é o custo elevado da tecnologia em comparação com baciloscopia e a necessidade de calibração anual, que é susceptível de ser difícil em ambientes remotos. ${ }^{12,15,17}$

No entanto, a Foundation for Innovative New Diagnostics (FIND) negociou reduções substanciais nos custos para uso no setor público em 116 países de alta carga de tuberculose e de baixa e média renda. 0 custo de capital inicial para 0 instrumento GeneXpert nesses ambientes (cerca de US\$ 17.500 por instrumento de 4 módulos) é consideravelmente maior do que para microscopia (cerca de US $\$ 1.500$ por diodo emissor de luz [LED] microscópio), mas muito menor do que para a cultura convencional, especialmente tendo em vista que se pode dispensar a necessidade de caros equipamentos de biossegurança. ${ }^{15}$

Apesar da baciloscopia ser o teste de diagnóstico mais utilizado no mundo, apenas 45\% dos casos de TB que foram notificados em 2009 foram com baciloscopia positiva, e estes representavam somente $28 \%$ da carga total estimado da doença incidente globalmente. ${ }^{12}$ Apesar de ser um procedimento simples, rápido e barato, sua sensibilidade varia de 40 a $80 \%$, dependendo de fatores como o tipo de lesão, o tipo e número de amostras, a atenção e a persistência do microscopista e a presença de co-infecção com HIV. ${ }^{15}$ Além disso, a baciloscopia, ao contrário do TRM-TB, não diferencia as cepas de $M$. tuberculosis resistentes ao tratamento e tampouco as discrimina de outras micobactérias atípicas. $^{18}$

A cultura é o método diagnóstico considerado padrão ouro para confirmação da tuberculose, com elevada sensibilidade e especificidade para o diagnóstico da tuberculose. Contudo, é pouco utilizada no processo de tomada de decisão clínica com relação ao tratamento inicial, devido à demora para obtenção do resultado, em virtude da reprodução lenta do bacilo. Além disso, necessita de cara infraestrutura em biossegurança. ${ }^{19}$

Os resultados do estudo ${ }^{12}$ evidenciaram sensibilidade e especificidade superior do teste $X$ pert ${ }^{\circledR}$ MTB/RIF em relação à baciloscopia e cultura. Quanto à especificidade, os resultados obtidos com o Xpert ${ }^{\circledR}$ MTB/RIF variaram de $90,9 \%$ a $100 \%$, em relação à cultura, indicando uma elevada capacidade do teste de diferenciar o M. tuberculosis dos demais tipos de micobactérias. Já a sensibilidade do teste, para as amostras com resultados positivos à baciloscopia, variou de $57 \%$ a $87 \%$, representando agilidade na confirmação do resultado, já que o tratamento poderia ser iniciado mais brevemente, sem a necessidade de se aguardar a confirmação pela cultura. 


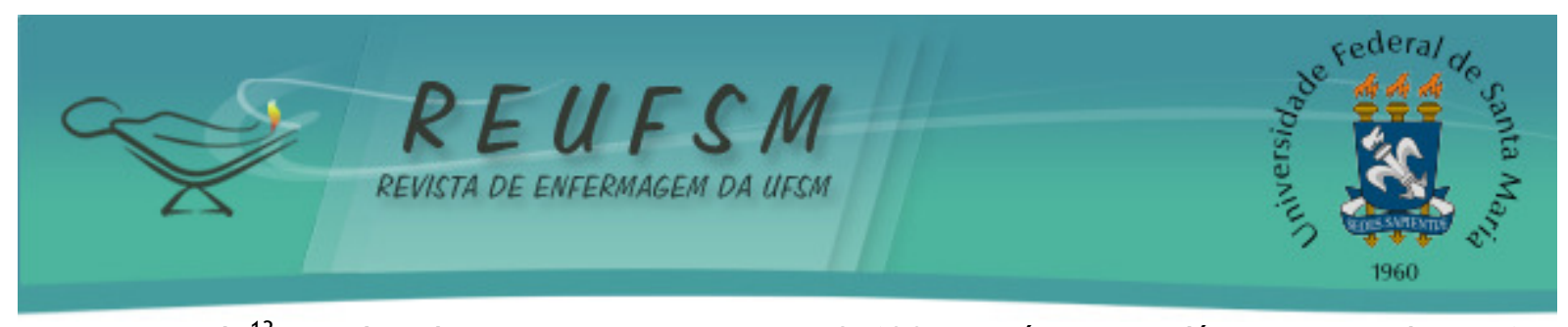

Estudo $^{13}$ realizado na Turquia com 2.639 espécimes clínicos, sendo 1.611 pulmonares e 1.028 extrapulmonares, mostrou sensibilidade e especificidade de $73,9 \%$ e $98,6 \%$, respectivamente. A sensibilidade e a especificidade foram de $100 \%$ e $76,2 \%$ para o esfregaço positivo de espécimes pulmonares; $100 \%$ e 20\% para espécimes extrapulmonares com baciloscopia positiva; 47,8\% e 99,1\% para espécimes pulmonares com esfregaço negativo; e $28,2 \%$ e $99,2 \%$ para exame extrapulmonar com baciloscopia negativa. A sensibilidade e a especificidade da baciloscopia foram $56,7 \%$ e $98,7 \%$ para todos os espécimes.

Em contraponto, estudo ${ }^{20}$ evidenciou baixa sensibilidade do Xpert ${ }^{\circledR}$ MTB/RIF, apesar de excelente especificidade, nas amostras de líquido pleural, sugerindo ser um teste impróprio para uso rotineiro na prática clínica de diagnóstico da tuberculose pleural. Segundo os autores, uma das possíveis razões para a baixa sensibilidade dos testes baseados em PCR é que derrames pleurais estão relacionados a uma reação inflamatória local. Além disso, o resultado encontrado também poderia ser explicado pelo tempo de armazenamento longo em congeladores, apesar de a temperatura ótima $\left(-80^{\circ} \mathrm{C}\right)$.

O Ministério da Saúde ${ }^{21}$ não incluiu o líquido pleural como amostra recomendada para realização do TRM-TB.

Já estudos ${ }^{15}$ em laboratório na Alemanha, França e Espanha têm avaliado a utilidade do Xpert $^{\circledR}$ MTB/RIF para o diagnóstico da tuberculose em amostras não respiratórias, incluindo fluido pleural, fluido gástrico, tecido, líquor, urina e fezes, com resultados compatíveis com os de amostras respiratórias com baciloscopia negativa. Semelhante a estudos de TB pulmonar, a sensibilidade foi maior para os espécimes baciloscopia positiva (96\%) em comparação com espécimes baciloscopia negativa (64\%). Os autores indicam a utilidade do Xpert ${ }^{\circledR}$ MTB/RIF para o diagnóstico de TB extrapulmonar, contudo, sugerem que outras avaliações prospectivas de suspeitos clínicos são necessárias para definir mais precisamente o utilitário para diferentes formas de doença extrapulmonar.

Estudo realizado na Coreia $^{22}$ relatou sensibilidade e especificidade da baciloscopia de $56,8 \%$ e $99,6 \%$, respectivamente. Enquanto, a sensibilidade e especificidade do Xpert $^{\circledR}$ MTB/RIF para a cultura sólida foram $97,2 \%$ e $72,4 \%$, respectivamente, enquanto que os dados correspondentes para a cultura líquida foi de $93,5 \%$ e $97,2 \%$.

Estudo $^{23}$ realizado em Blumenau, demonstrou que das 117 amostras analisadas, três $(2,56 \%)$ apresentaram baciloscopia positiva e Xpert ${ }^{\circledR}$ MTB/RIF positiva para $M$. tuberculosis (concordância de $100 \%)$, e nove $(7,69 \%)$ tiveram crescimento na cultura. Das seis amostras que tiveram resultado positivo somente por cultura, uma foi identificada ainda como pertencente ao complexo M. tuberculosis, e outra foi identificada como micobactéria não tuberculosa. A sensibilidade e a especificidade da baciloscopia e da PCR em relação à cultura foram $33,3 \%$ e $100 \%$, respectivamente.

Apesar de ser um excelente método de diagnóstico, o estudo ${ }^{19}$ evidencia que um resultado negativo de Xpert $^{\circledR}$ MTB/RIF é insuficiente para descartar TB ativa, quando persistir suspeita clínica. Dessa forma, é preciso esclarecer que a clínica do paciente é soberana em relação aos exames de diagnóstico.

Em relação à resistência da $M$. tuberculosis aos medicamentos, sabe-se que representa uma grave ameaça para o controle da TB. Estima-se que aproximadamente $7 \%$ dos casos são diagnosticados. Essa baixa taxa reflete a deficiência na capacidade dos laboratórios de diagnóstico em realizar a cultura para TB, devido ao alto custo, complexidade técnica e requisitos de infraestrutura. ${ }^{15}$

O Xpert ${ }^{\circledR}$ MTB/RIF trouxe a possibilidade de mudar essa triste realidade, visto que detecta, simultaneamente, $M$. tuberculosis e a resistência à rifampicina, principal medicamento no combate à TB, pela amplificação, por meio de PCR, de cinco sondas 


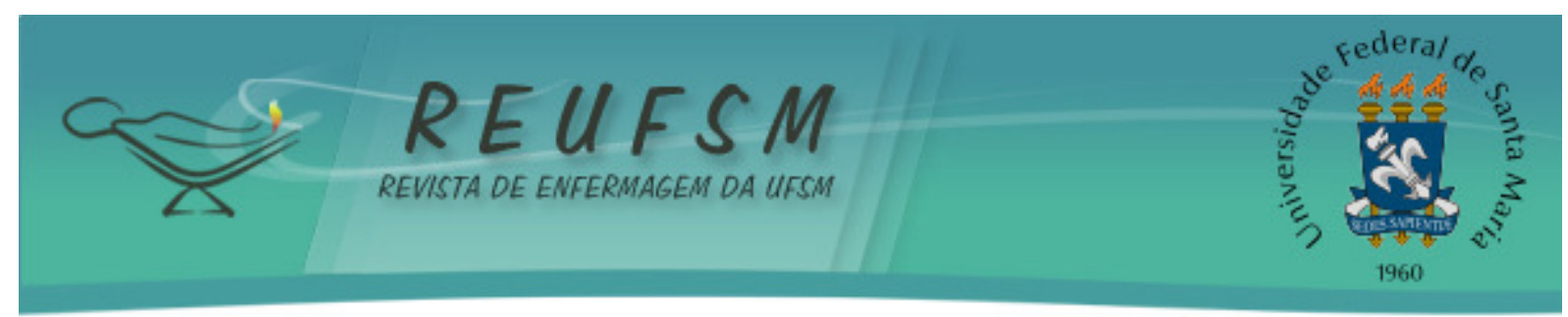

sobrepostas que são complementares à região determinante da resistência à rifampicina, composta por 81 pares de bases do gene rpoB de M. tuberculosis. Em seguida, esta região é examinada com o objetivo de identificar mutações associadas à resistência à Rifampicina. ${ }^{12,15,23}$

Porém, o estudo esclarece que apesar de sua capacidade de identificar mutações associadas à resistência à rifampicina, o fato de o bacilo ter a mutação não significa que ele, de fato, será resistente ao medicamento. Ademais, nem todas as cepas resistentes à Rifampicina possuem mutações na região alvo do teste. Por isso, o uso de testes moleculares na triagem rápida de $M$. tuberculosis resistente não dispensa a confirmação por testes de sensibilidade. ${ }^{12,23}$

Em estudo americano, ${ }^{15}$ três amostras foram falso-positivas para resistência à rifampicina. Similares resultados falso-positivos também foram relatados a partir de estudos na África do Sul, incluindo o estudo de implementação FIND. Também foi verificado divergência dos resultados de resistência à Rifampicina fornecidos pelo Xpert ${ }^{\circledR}$ MTB/RIF e pela cultura no estudo realizado na Turquia. ${ }^{13}$

Como não há relato na literatura acerca do manuseio clínico do Xpert ${ }^{\circledR}$ MTB/RIF na abordagem de paciente suspeito de TB pulmonar resistente, a OMS recomenda que, quando resistência à Rifampicina é detectada pelo Xpert $^{\circledR}$ MTB/RIF, uma investigação mais aprofundada e de sensibilidade às drogas, baseada em cultura de drogas de primeira e segunda linha deve ser feita. ${ }^{12,15}$

No Brasil, o Ministério da Saúde, implantou o uso do teste para diagnóstico em pacientes adultos suspeitos de TB pulmonar e de TB pulmonar resistente, não em substituição a baciloscopia, mas como um método de ajuda para um diagnóstico mais rápido. A baciloscopia ainda será utilizada no diagnóstico e no acompanhamento no tratamento da tuberculose, já que o resultado positivo não necessariamente indica a presença de organismos viáveis, tendo em vista que a PCR identifica material genético de microrganismos vivos ou mortos. ${ }^{12}$

Ao destacar as contribuições para a enfermagem, neste estudo, valoriza-se a historicidade que liga o trabalho dos enfermeiros às ações de prevenção e controle da TB. Junto a isso, ressalta-se a importância do conhecimento científico acerca dos métodos diagnósticos, a fim de avançar na produção de conhecimentos em Enfermagem, propondo pensar inovações, ou seja, a incorporação de novos conhecimentos e práticas nos serviços de saúde. ${ }^{24}$

\section{CONCLUSÃO}

A capacidade de se detectar mutações resistentes à Rifampicina em amostras clínicas, o menor tempo de processamento das amostras, e sua maior sensibilidade e especificidade em relação à baciloscopia, são consideradas vantagens importantes do Xpert MTB/RIF. 0 uso do teste para o diagnóstico rápido da tuberculose representa um avanço significativo.

O estudo proporcionou uma análise relevante acerca do tema, contribuindo para a construção de um conhecimento científico que possa dar suporte a melhores condutas na prática clínica. Como limitação do estudo, pode-se citar a quantidade reduzida de artigos disponíveis sobre o tema abordado, e que atendessem aos critérios de inclusão e exclusão adotados, motivo esse que levou a seleção de apenas 15 artigos.

Conclui-se que a partir do conhecimento sobre este novo método de diagnóstico, têm-se em mãos uma forma mais eficaz de controle da doença, tendo em vista que os resultados podem ser emitidos no mesmo dia da coleta. Para a enfermagem como responsável por atuar nas ações de identificação e controle da TB, o teste rápido Xpert 


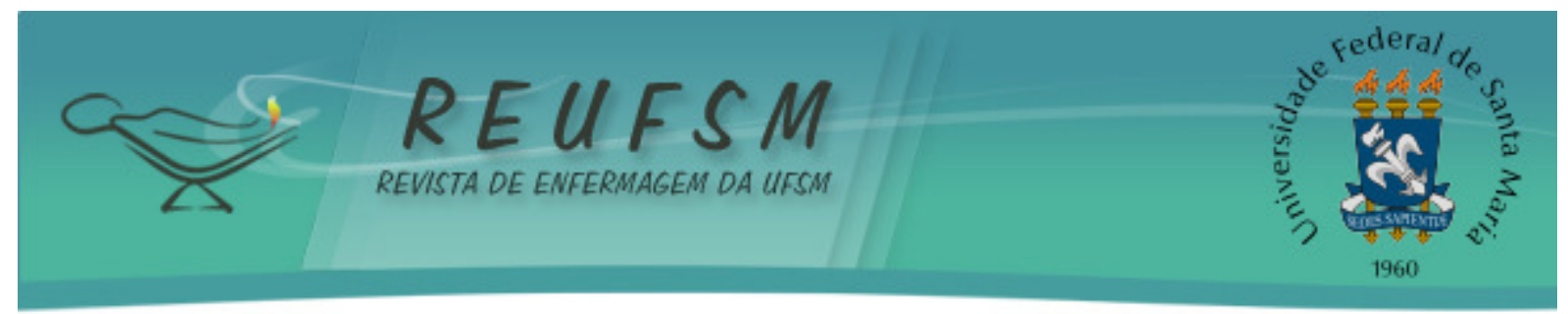

MTB/RIF, torna-se uma ferramenta de grande contribuição, pois possibilita o início mais rápido do tratamento e, por conseguinte, minimiza a disseminação da doença.

\section{REFERÊNCIAS}

1. World Health Organization. Global tuberculosis report [Internet]. Genebra: WHO, 2016 [acesso em 2016 nov 13]. Disponivel em: http://www.who.int/tb/publications/global_report/en/.

2. Hur YG, Crampin AC, Chisambo C, Kanyika J, Houben R, Ndhlovu R, et al. Identification of immunological biomarkers wich may differentiate latent tuberculosis from exposure to environmental nontuberculous mycobacteria on children. Clin Vaccine Immunol [Internet]. 2014 [acesso em 2016 mar 5];21(2):133-42. Disponivel em: http://www.ncbi.nlm.nih.gov/pubmed/24285818.

3. World Health Organization. Policy statement: automated real-time nucleic acid amplification technology for rapid and simultaneous detection of tuberculosis and rifampicin resistance: Xpert MTB/RIF system [Internet]. WHO/HTM/TB/2010 [acesso em 2016 mar 2]. Disponivel em: http://whqlibdoc.who.int/publications/2011/9789241501545_eng.pdf.

4. Abege G, Paasch F, Apers L, Rigouts L, Colebunders R. Tuberculosis drug resistance testing by molecular methods: opportunities and challenges in resource limited settings. J Microbiol Methods [Internet]. $2011 \mathrm{fev}$ [acesso em 2016 jan 25];84(2):155-60. Disponivel em: http://www.sciencedirect.com/science/article/pii/S0167701210003933.

5. Sudarsanam TD, Thayryan P. The accuracy of the Xpert $₫ M T B / R I F$ assay for detecting pulmonary tuberculosis and rifampicin resistance in adults: summary of the evidence and implications for public health programmes. Clin Epidemiol Glob Health [Internet]. 2013 ago [acesso em 2016 fev 20];1(2):78-84. Disponivel em: http://www.sciencedirect.com/science/article/pii/S2213398413000602.

6. Lin SG, Desmond EP. Molecular Diagnosis of Tuberculosis and Drug Resistance. Clin Lab Med [Internet]. 2014 jun [acesso em 2016 mar 25];34(2):297-314. Disponivel em: http://www.sciencedirect.com/science/article/pii/S0272271214000195.

7. Galvão CM, Mendes KDS, Silveira RCCP. Revisão integrativa: método de revisão para sintetizar as evidências disponíveis na literatura. In: Brevedelli MM, Sertório SCM.Trabalho de conclusão de curso: guia prático para docentes e alunos da área da saúde. São Paulo: látrica; 2010. p.105-26.

8. Ratinaud P. Iramuteq: interface de $\mathrm{R}$ pour les analyses multidimensionnelles de textes at de questionnaires: un logiciel libre construit avec des logiciels libres [Internet]. 2009 [acesso em 2015 jan 25]. Disponivel em: http://www.iramuteq.org.

9. Santos CMC, Pimenta CAM, Nobre MRC. A estratégia PICO para a construção da pergunta de pesquisa e busca de evidências. Rev Latinoam Enferm [Internet]. 2007 maio-jun [acesso em 2016 mar 25];15(3):508-11. Disponível em: http://www.scielo.br/pdf/rlae/v15n3/pt_v15n3a23.pdf.

10. Camargo BV, Justo AM. Tutorial para uso do software de análise textual IRAMUTEQ [Internet]. Florianopolis-SC: Universidade Federal de Santa Catarina, LACCOS ; 2013 [acesso em 2015 set 10]. Disponivel em: http://www.iramuteq.org/documentation/fichiers/tutoriel-en-portugais. 


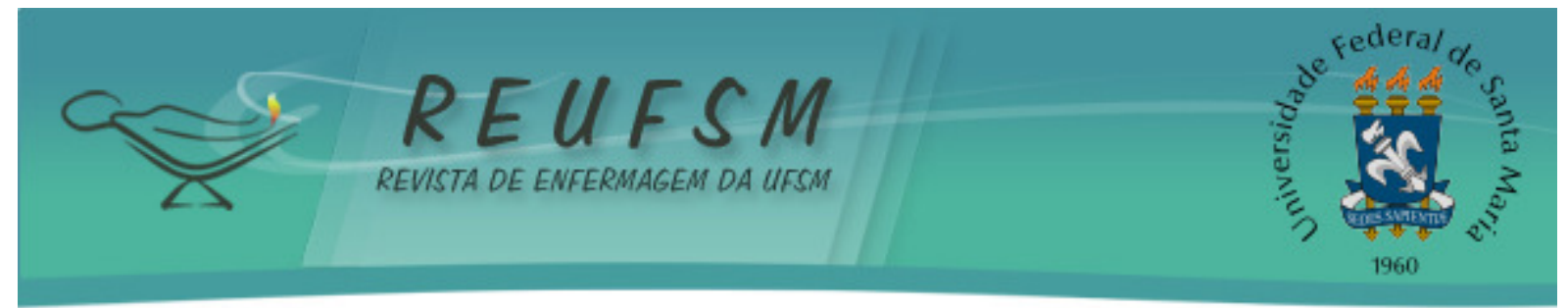

11. Cruz DALM, Pimenta CAM. Prática baseada em evidências, aplicada ao raciocínio diagnóstico. Rev Latino-am Enfermagem [Internet]. 2005 [acesso em $2017 \mathrm{fev}$ 1];13(3):41522. Disponível em: http://www.scielo.br/pdf/rlae/v13n3/v13n3a17.pdf.

12. Agência Nacional de Vigilância Sanitária. Xpert ${ }^{\circledR}$ MTB/RIF no diagnóstico da tuberculose pulmonar. Boletim Brasileiro de Avaliação de Tecnologias em Saúde [Internet]. 2011 set [acesso em 2016 mar 10];6(16). Disponível em: http://bvsms.saude.gov.br/bvs/periodicos/brats_16.pdf.

13. Özkütük $N$, Sürücüoğlu $S$. Orta prevalanslı bölgede akciğerve akciğer dișı tüberküloz tanısındas Xpert MTB/RIF testinin değerlendirilmesi. Mikrobiyol Bul [Internet]. 2014 [acesso em 2016 mar 15];48(2):223-32. Disponivel em: http://www.mikrobiyolbul.org/managete/fu_folder/2014-02/html/2014-48-2-223232.htm.

14. Brasil. Secretaria de Vigilância em Saúde. Departamento de Vigilância Epidemiológica. Manual de recomendações para o controle da tuberculose no Brasil. Brasília: Ministério da Saúde; 2011 [acesso em 2016 mar 20]. Disponível em: http://bvsms.saude.gov.br/bvs/publicacoes/manual_recomendacoes_controle_tuberculose _brasil.pdf. (Série A. Normas e manuais técnicos).

15. Lawn SD, Nicol MP. Xpert ${ }^{\circledR}$ MTB/RIF assay: development, evaluation and implementation of a new rapid molecular diagnostic for tuberculosis and rifampicin resistance. Future Microbiol [Internet]. 2011 [acesso em 2016 fev 20];6(9):1067-82. Disponivel em: http: //www.futuremedicine.com/toc/fmb/6/9.

16. You JHS, Lui G, Kam KM, Lee NLS. Cost-effectiveness analysis of the Xpert MTB/RIF assay for rapid diagnosis of suspected tuberculosis in an intermediate burden area. $\mathrm{J}$ Infect [Internet]. 2015 [acesso em 2016 abr 4];70(4):409-14. Disponivel em: http://www.sciencedirect.com/science/article/pii/S016344531500002X.

17. Park S, Kim C, Jeong H, Son H, Kim S, Park M. Evaluation and comparison of molecular and conventional diagnostic tests for detecting tuberculosis in Korea, 2013. Osong Public Health Res Perspect [Internet]. 2014 [acesso em $2017 \mathrm{fev}$ 03];5 Supl:53-7. Disponivel em: https://www.ncbi.nlm.nih.gov/pmc/articles/PMC4301634/.

18. Hur Y, Kang YA, Jang S, Hong JY, Kim Aa, Lee SA, et al. Adjunctive biomarkers for improving diagnosis of tuberculosis and monitoring therapeutic effects. J Infection [Internet]. 2015 [acesso em 2017 fev 02];70(4):346-55. Disponivel em: http://www.sciencedirect.com/science/article/pii/S016344531400334X.

19. Jafari C, Ernst B, Kalsdorf B, Lange C. Comparison of molecular and immunological methods for the rapid diagnosis of smear-negative tuberculosis. Int J Tuberc Lung Dis [Internet]. 2013 [acesso em 2017 fev 03];17(11):1459-65. Disponivel em: https://www.ncbi.nlm.nih.gov/pubmed/24125451.

20. Trajman A, Oliveira EFSSK, Bastos ML, Belo Neto E, Silva EM, Lourenço MCS, et al. Accuracy of polimerase chain reaction for the diagnosis of pleural tuberculosis. Respiratory Medicine [Internet]. 2014 [acesso em $2017 \mathrm{fev}$ 02];108(6):918-23. Disponivel em: http://www.sciencedirect.com/science/article/pii/S0954611114001504.

21. Brasil. Ministério da Saúde. Secretaria de Vigilância em Saúde, Departamento de Vigilância das Doenças Transmissíveis. Nota informativa $n^{\circ} 9$, de 2014. Recomendações sobre o diagnóstico da tuberculose por meio do teste rápido molecular para tuberculose. 


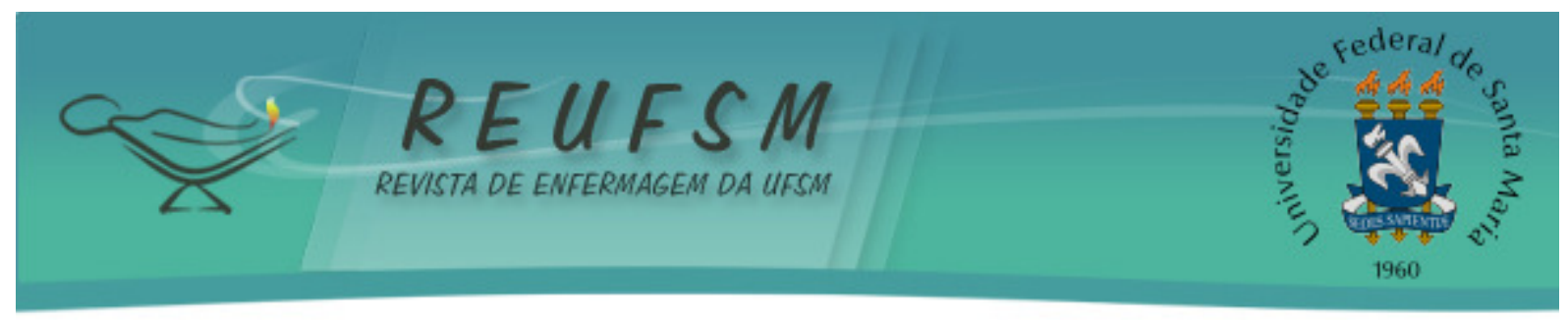

Brasília: Ministério da Saúde; 2014 [acesso em 2017 fev 03]. Disponivel em: http: / / www.riocomsaude.rj.gov.br/Publico/MostrarArquivo.aspx?C=tOjQoGNWGNw\%3D.

22. Park S, Kim C, Jeong H, Son H, Kim S, Park M. Evaluation and comparison of molecular and conventional diagnostic tests for detecting tuberculosis in Korea, 2013. Osong Public Health Res Perspect [Internet]. 2014 [acesso em $2017 \mathrm{fev}$ 03];5 Supl:53-7. Disponivel em: https://www.ncbi.nlm.nih.gov/pmc/articles/PMC4301634/.

23. Marchi AM, Juttel ID, Kawacubo EM, Dalmarco EM, Blatt SL, Cordova CMM. Evaluation of methods for detection and identification of Mycobacterium species in patients suspected of having pulmonar Tuberculosis. Braz J Microbiol [Internet]. 2008 [acesso em $2017 \mathrm{fev}$ 03];39(4):613-18. Disponivel

em: http://www.scielo.br/scielo.php?script=sci_arttext\&pid=S1517-83822008000400003.

24. Souza KMJ, Sá LD, Silva, LMC, Palha PF. Atuação da enfermagem na transferência da política do tratamento diretamente observado da tuberculose. Rev Esc Enferm USP [Internet]. 2014 [acesso em 2016 nov 18];48(5):874-82. Disponivel em: http://www.scielo.br/pdf/reeusp/v48n5/pt_0080-6234-reeusp-48-05-874.pdf.

Data de recebimento: 20/04/2016

Data de aceite: 13/02/2017

Autor principal: Daniela Furtado Rodrigues de Andrade, email: daniela.furtado@outlook.com, Endereço postal: Av. Frei Serafim, 2280 - Centro (Sul), Teresina - PI, 64001-020. 